$1 \cdot 7$

اتجاهات زراع الموالح نحو المكافحة الحيوية لحشرة صانعة أنفاق أوراق المو الح بالنوبارية

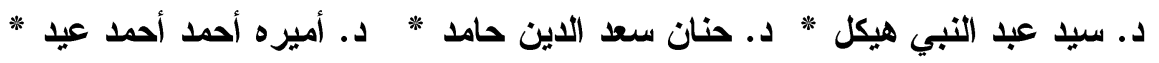

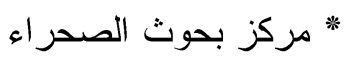

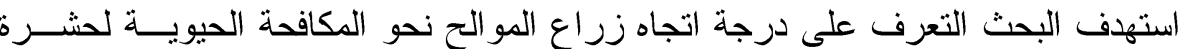

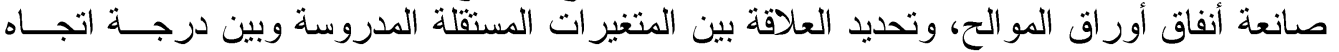

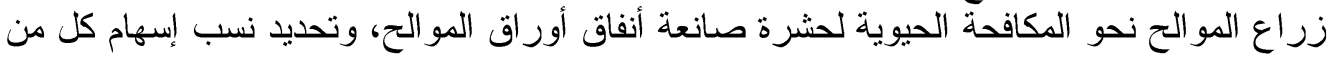

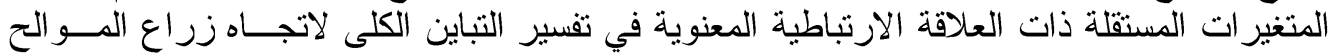

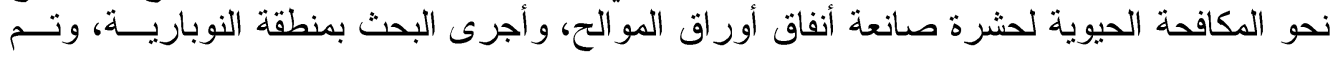

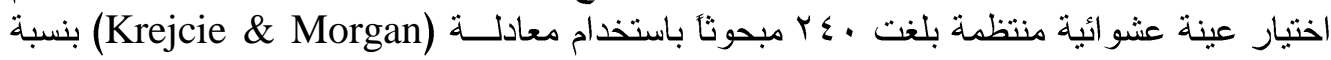

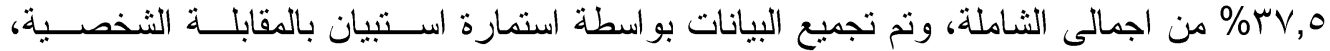

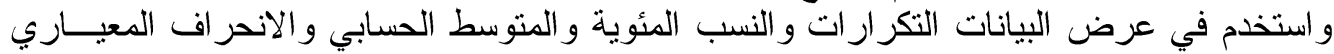

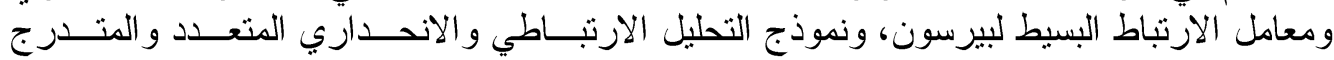

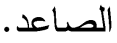

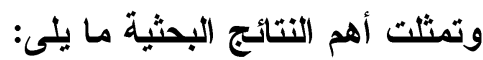

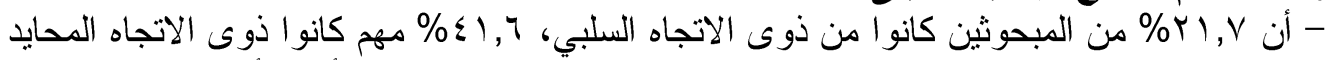

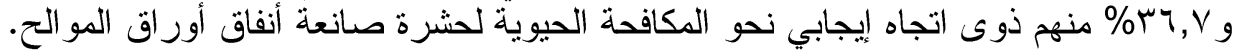

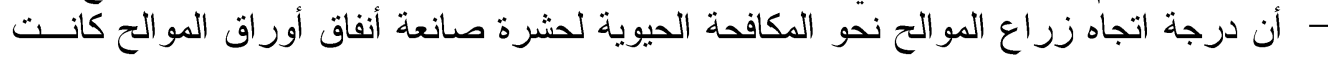

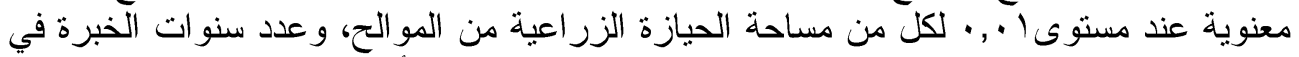

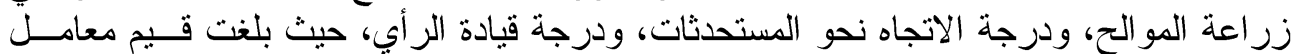

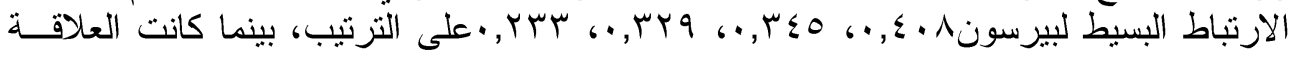

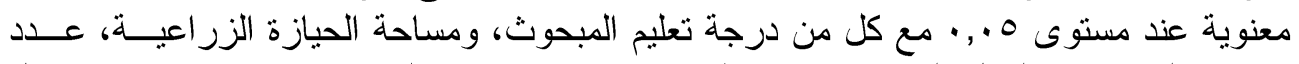

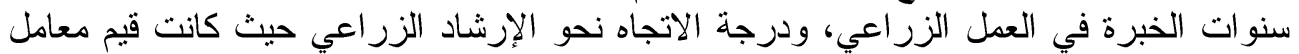

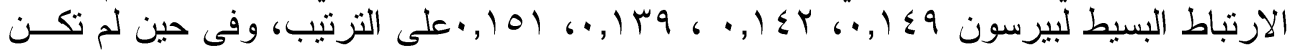

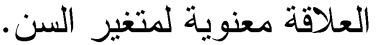

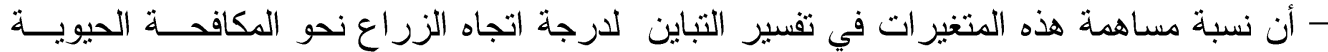

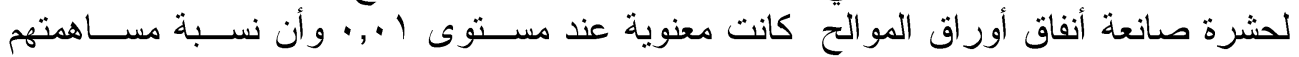

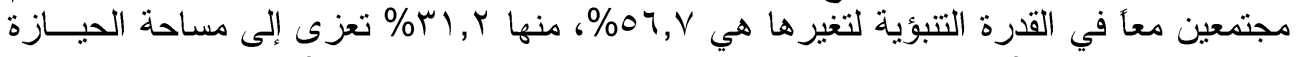

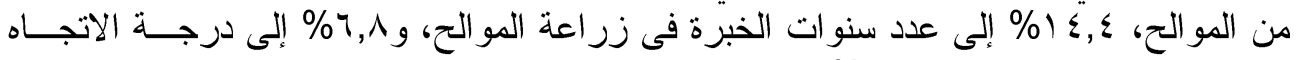

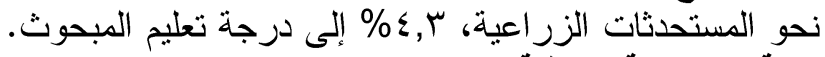

المقدمة و المشكلة البحثية الزية

تشهد مصر في الوقت الحالي تغيرات أساسيه في جميع سياستها وبر امجها ومشــرو عاتها،

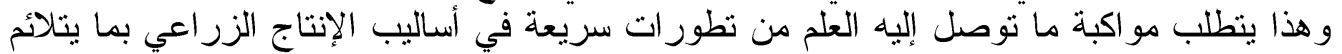

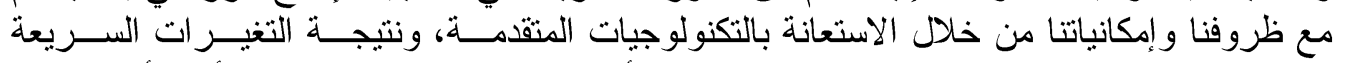

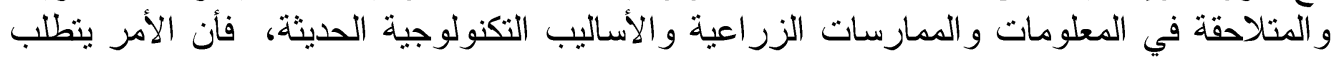

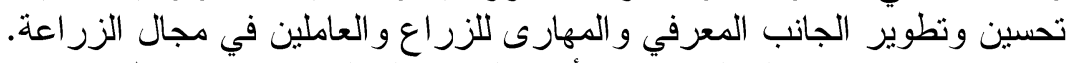

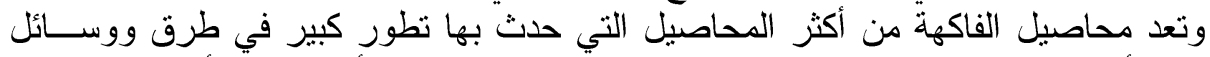

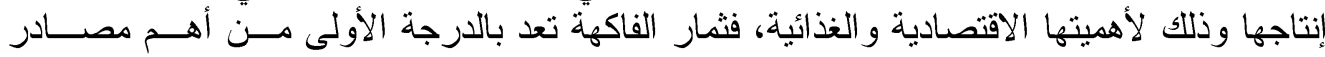

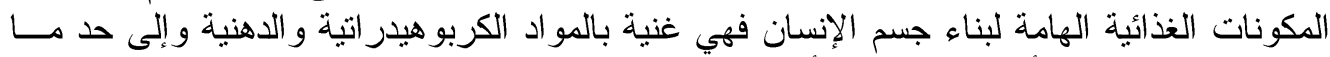

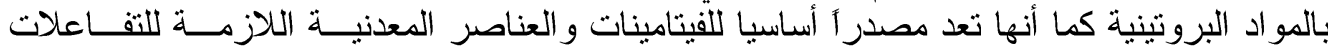

Fayoum J. Agric. Res. \& Dev., Vol. 30, No.2, July, 2016 
$1 \cdot v$

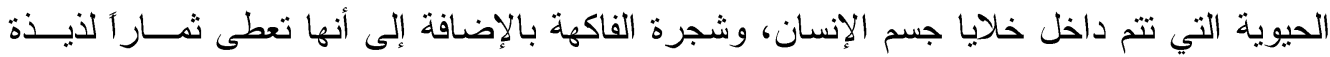

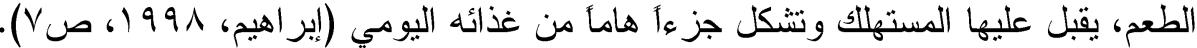

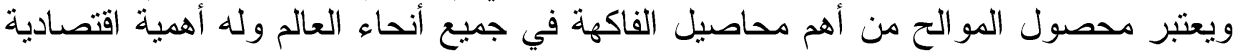

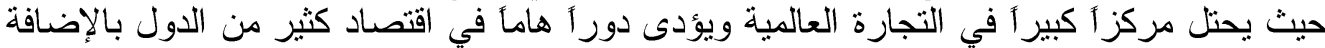

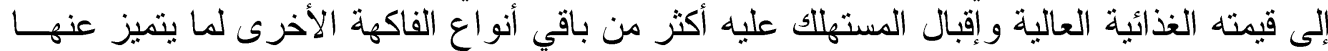

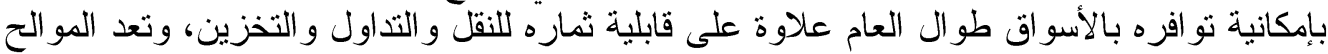

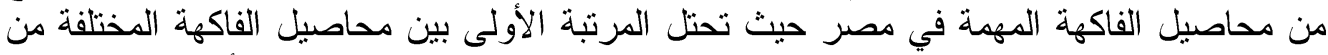

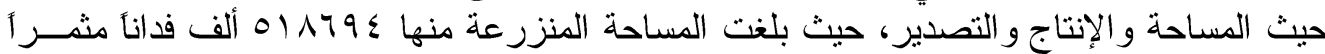

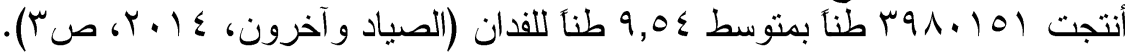

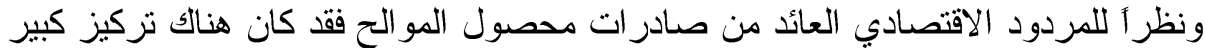

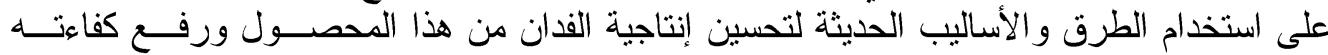

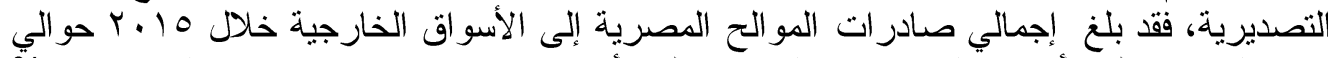

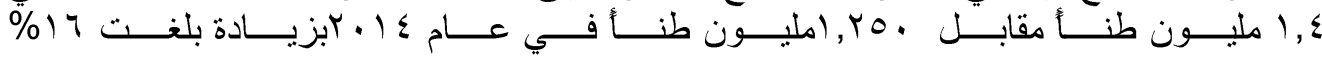
.(/http://Www.alborsanews.com)

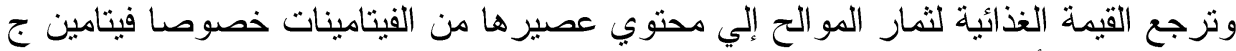

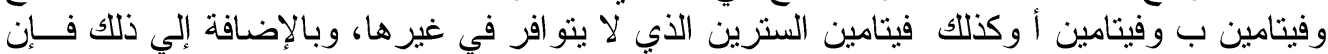

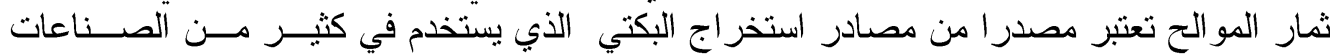

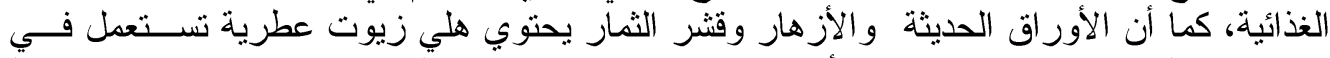

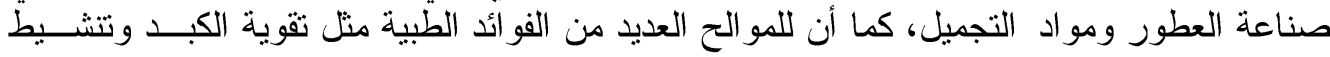

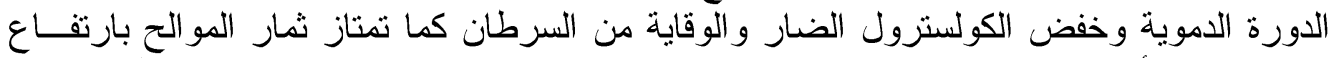

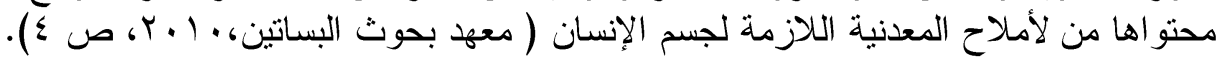

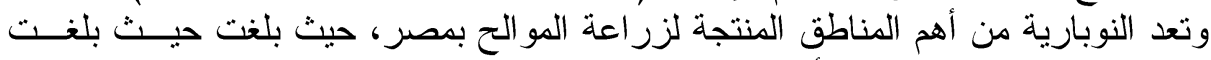

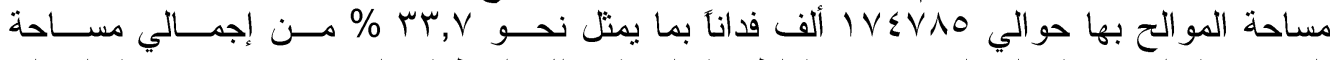

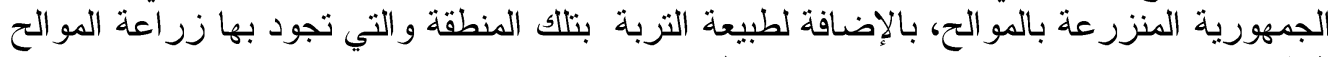

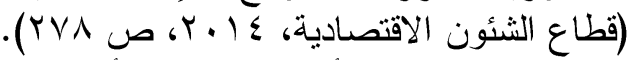

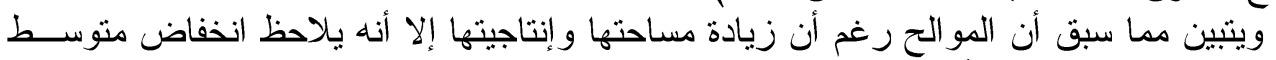

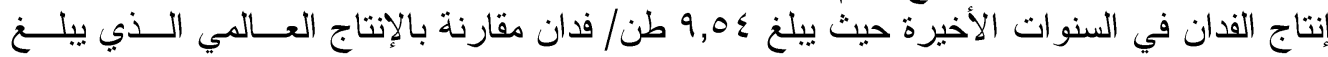

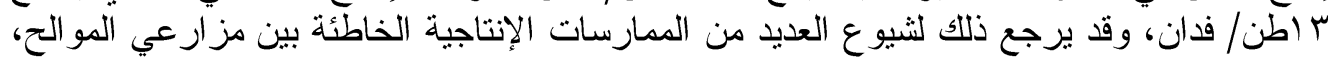

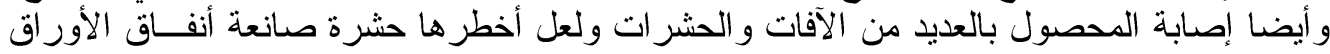

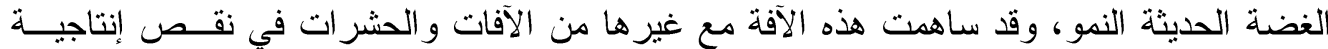

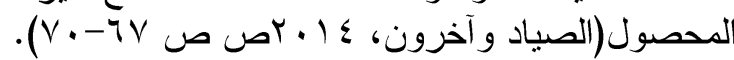

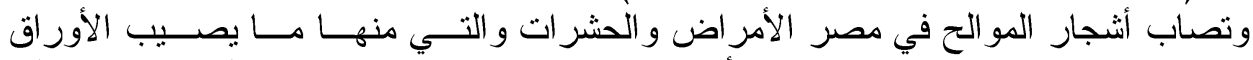

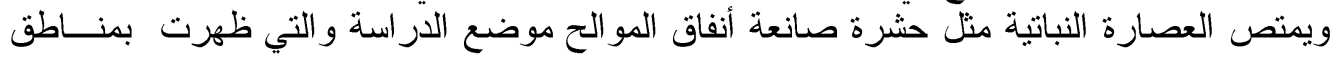

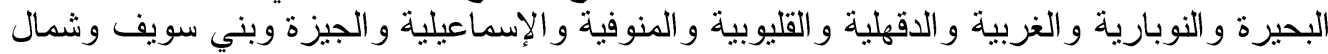

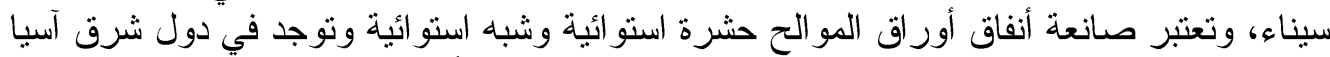

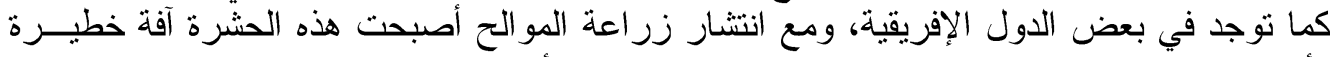

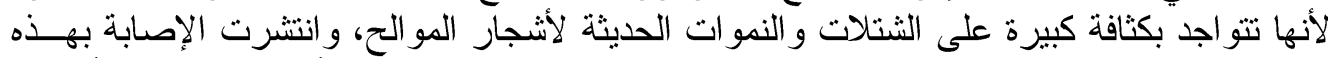

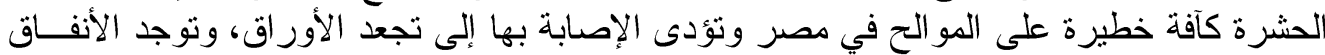

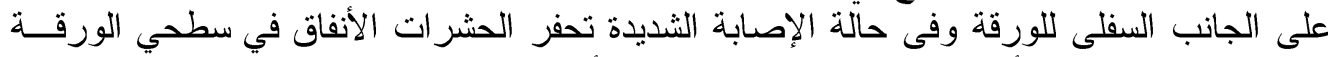

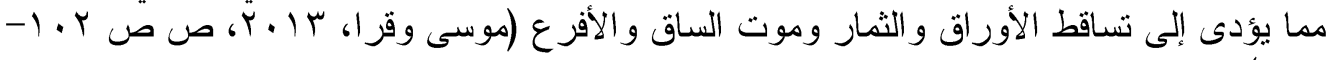

Fayoum J. Agric. Res. \& Dev., Vol. 30, No.2, July, 2016 
$1 \cdot \Lambda$

و اتضح أن هناك العديد من المخاطر المرتبطة بمكافحة الآفات الزر اعية من خلال استخدام

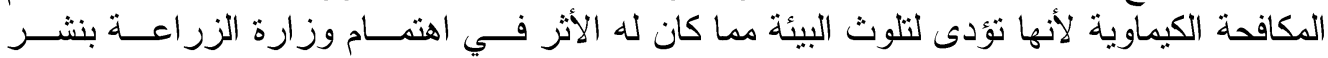

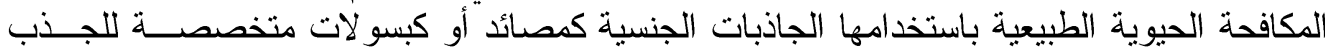

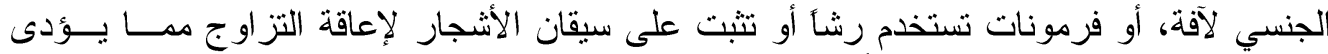

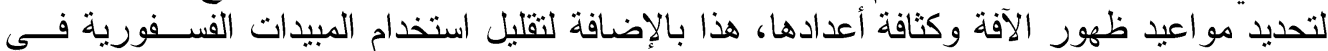
أوقات نشاط الأعداء الحيوية، حيث أن المكافحة الحيوية هي الأمل في القضاء القياء على الآفات الحشريةّ

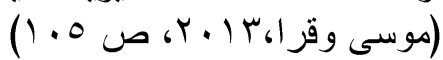

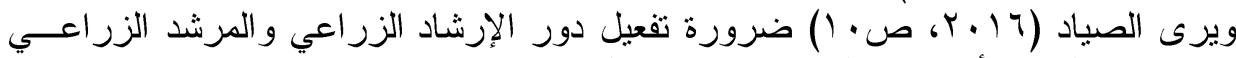

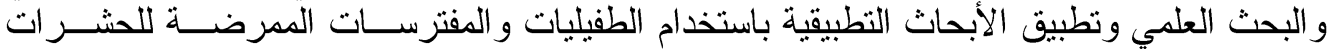

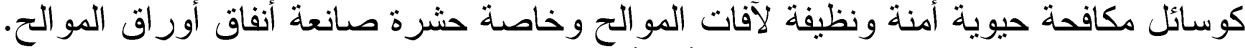

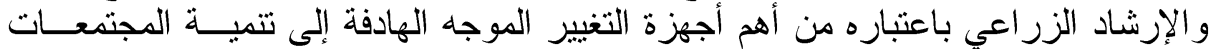

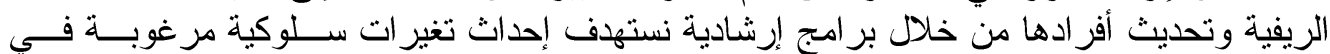

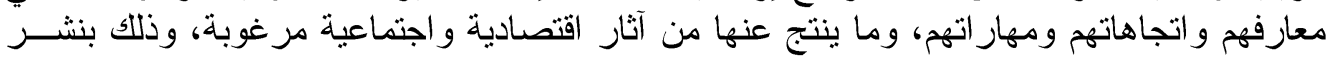

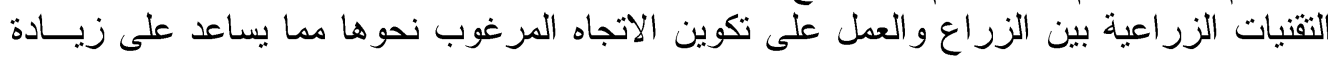

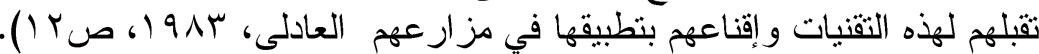

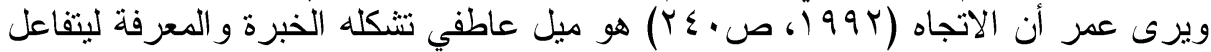

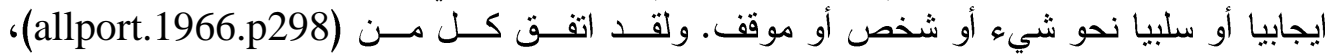

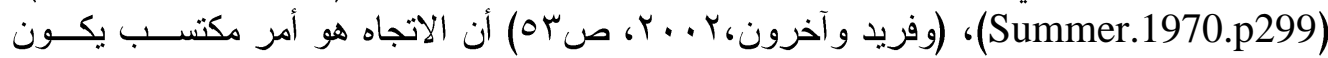

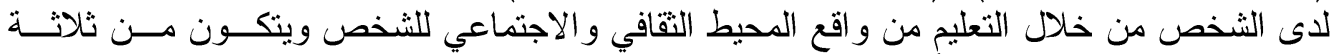

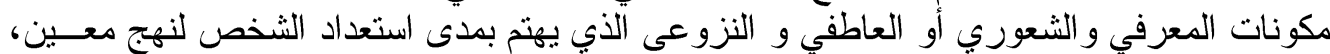

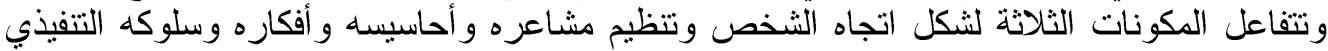
في البيئة المحيطة به.

ونظر أ لأهمية محصول المو الح باعتباره متصدر أ لمحاصيل الفاكهة المصرية مساحة و إنتاجاً

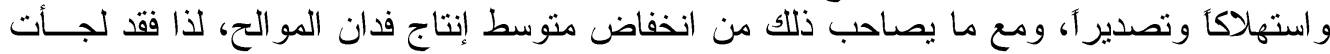

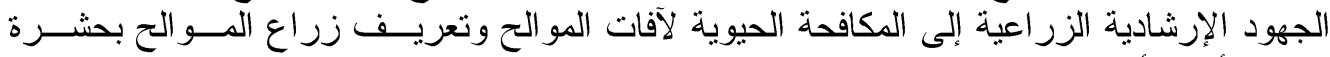

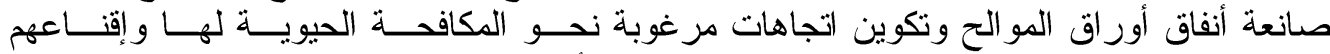
باستخدامها وتطبيقها في حقولهم، لذا برزت الحاجة إلى أجراء هذا البحث لتحديد مستوى اتجاهـــات

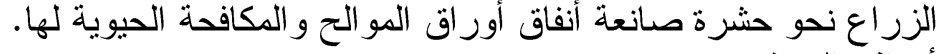

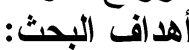

تمشياً مع العرض السابق فقد تحددث أهداف البحث فيما يلي:-

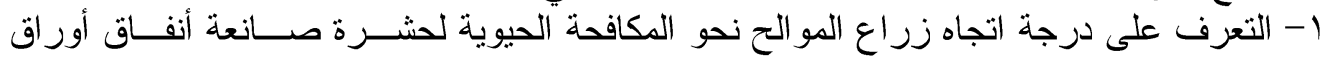

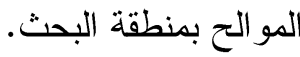

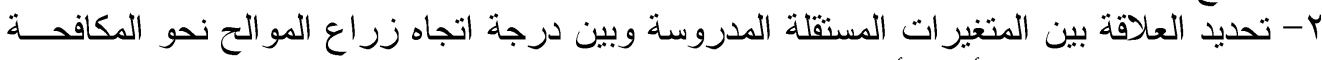

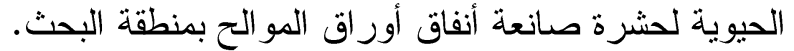
ب- تحديد نسب إسهام كل من المتغيرات المستقلة ذات العلاقة الارتباطية المعنوية في تفسير التباين

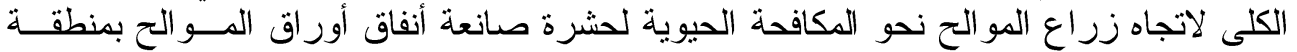




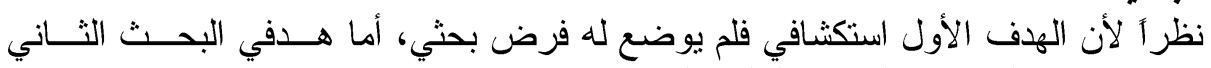

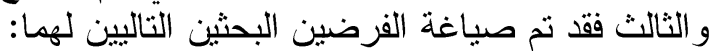

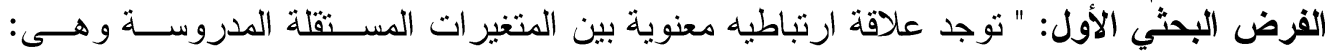

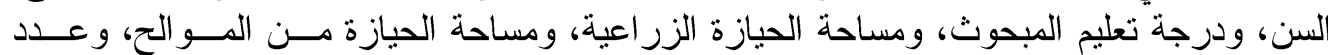

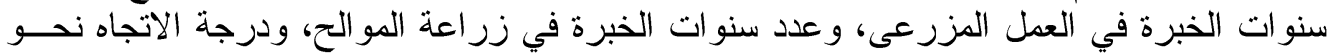

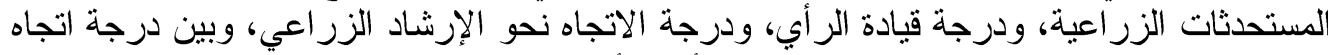

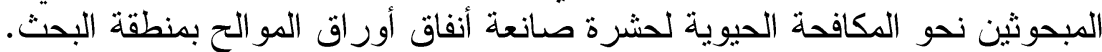

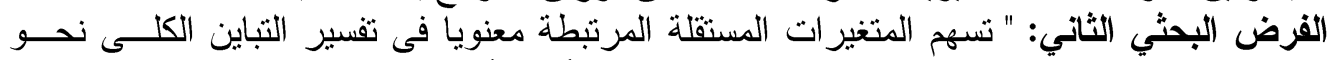

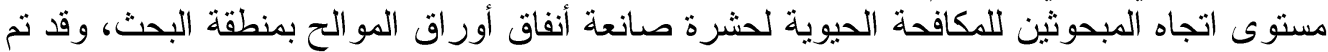

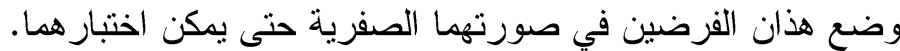

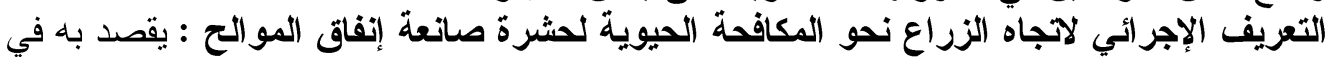

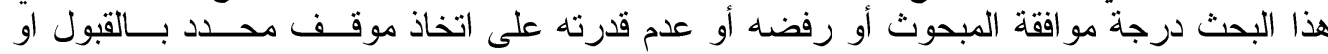

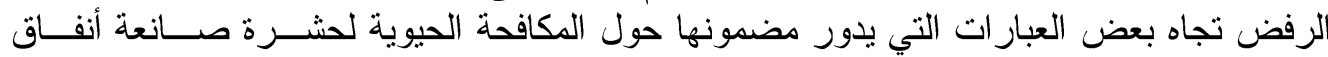

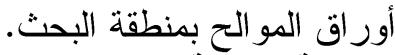
الطريقة البحثية البرة

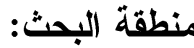

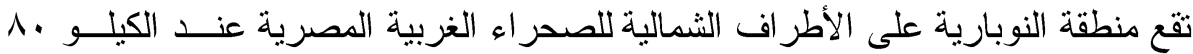

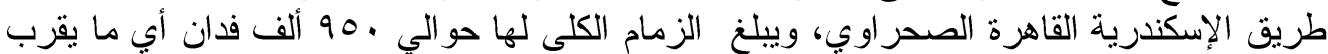

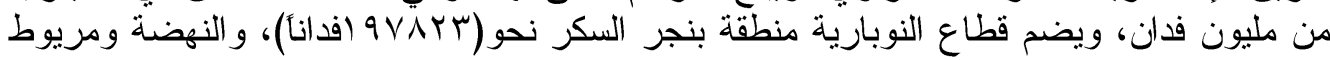

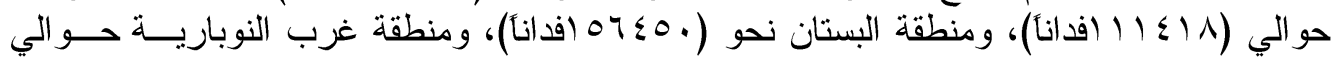
(Y IVT) .$(r \cdot 17$

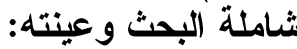

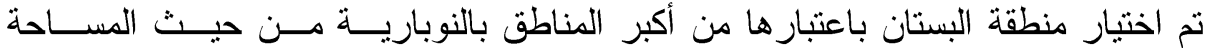

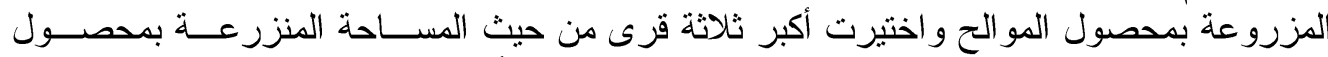

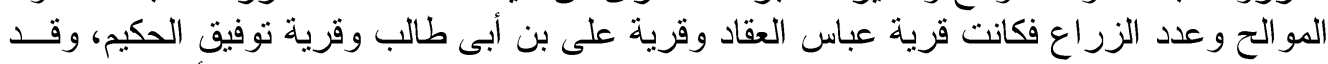

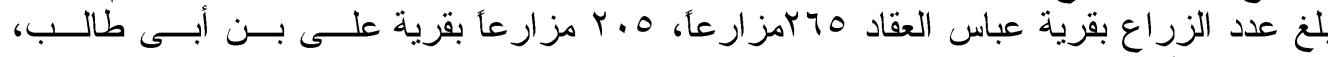

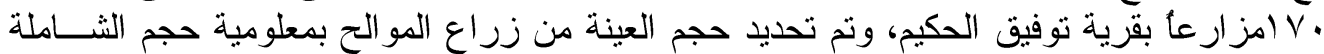

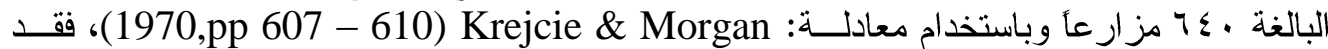

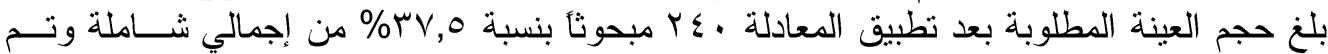

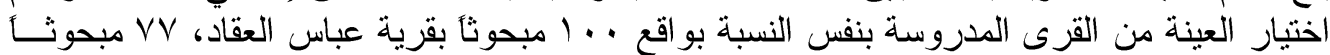

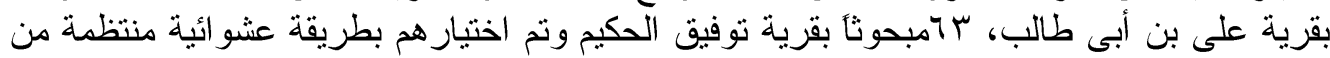

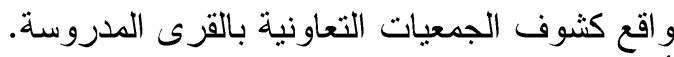

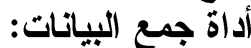

تم جمع بيانات هذا البحث عن طريق المقابلة الثخصية للمبحوثين بواسطة استمارة استبيان

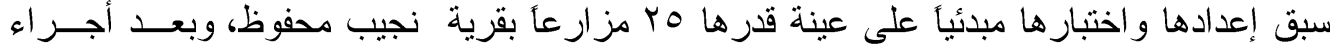

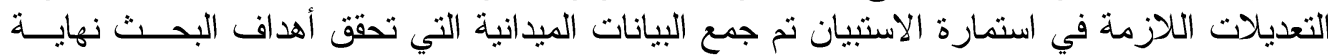

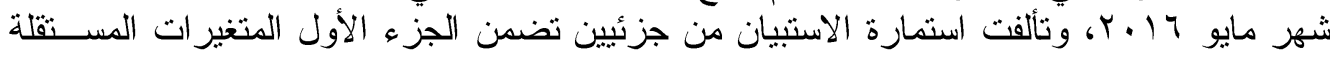

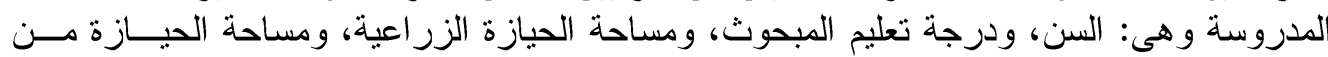

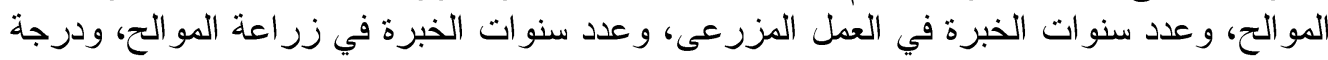

Fayoum J. Agric. Res. \& Dev., Vol. 30, No.2, July, 2016 
11.

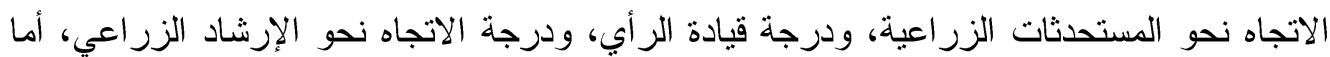

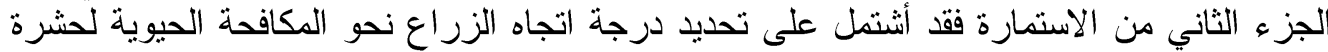

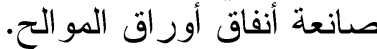

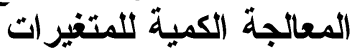

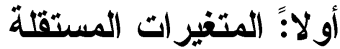

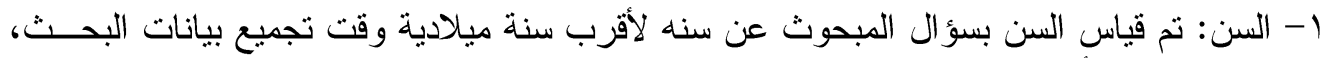

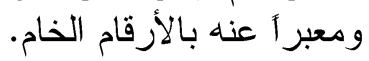

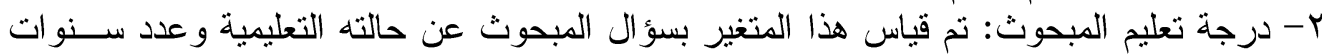

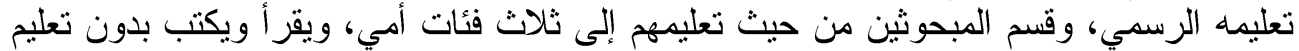

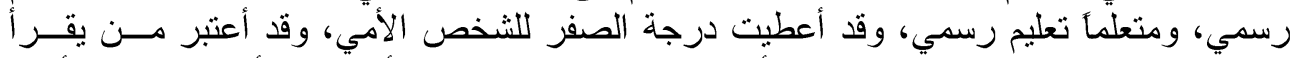

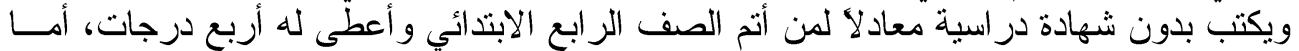

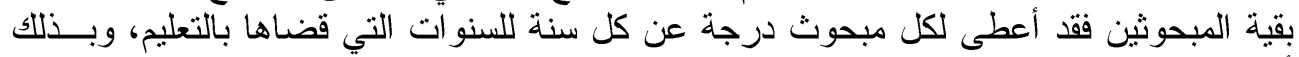

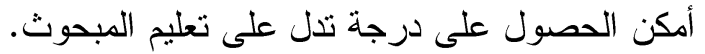

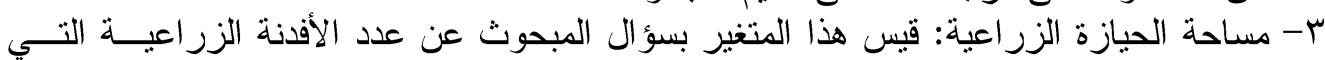

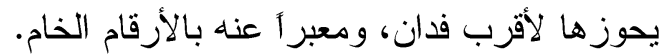

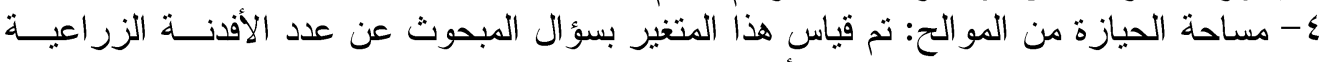

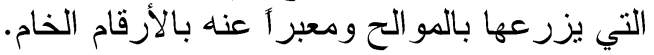

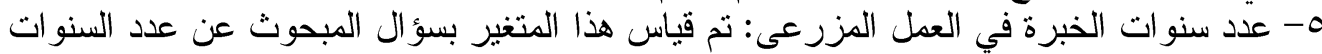

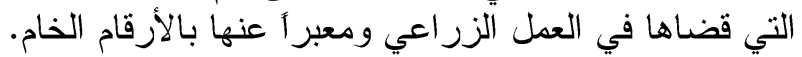

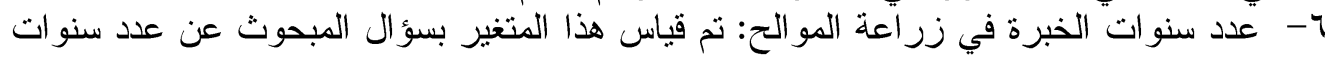

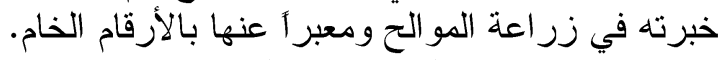

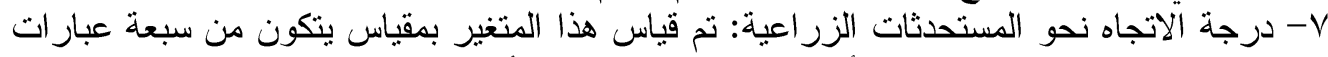

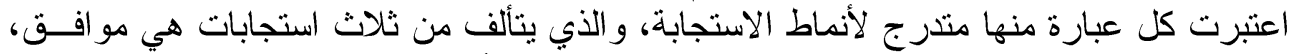

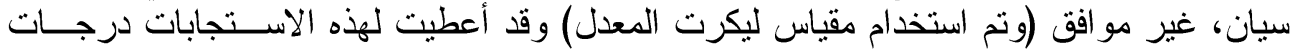

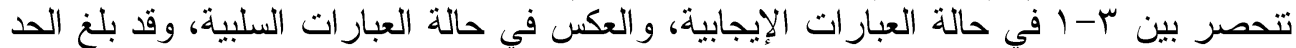

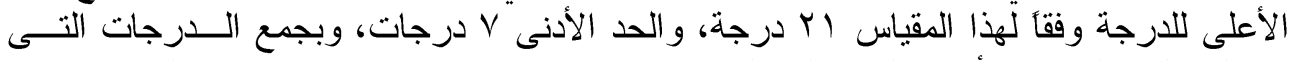

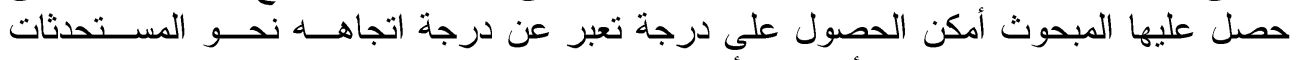

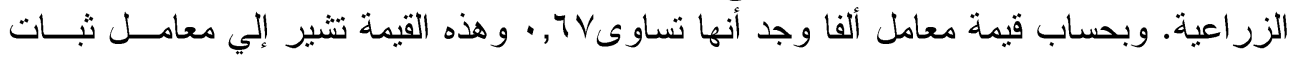
مقبول.

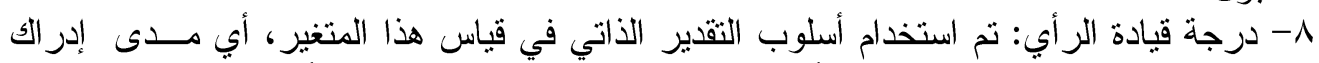

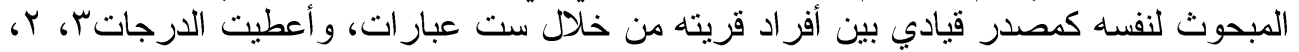

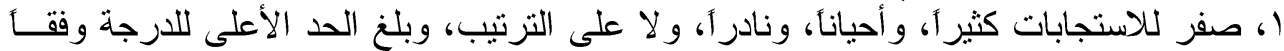

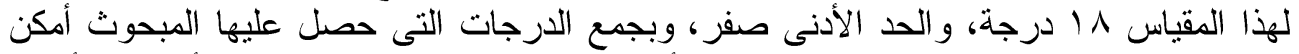

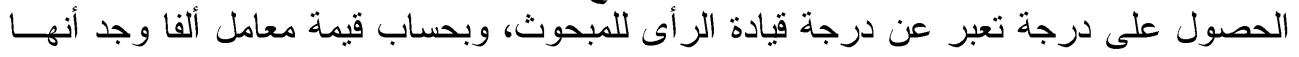

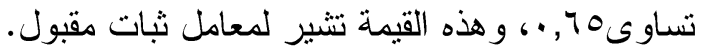

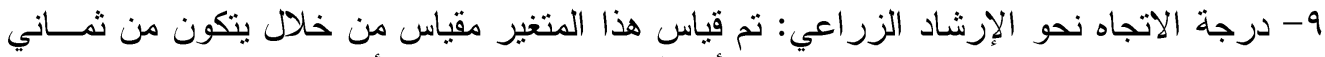

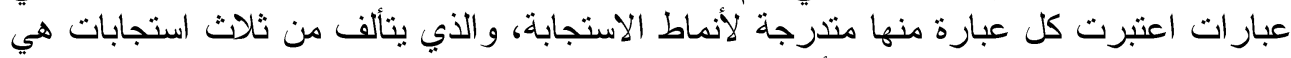

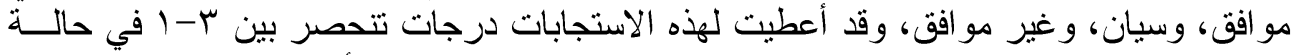

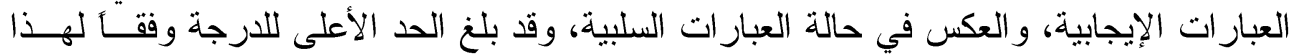

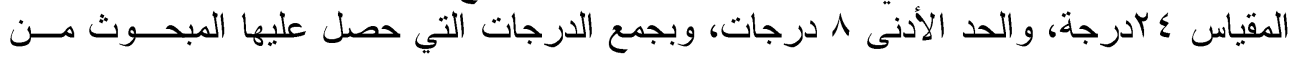

Fayoum J. Agric. Res. \& Dev., Vol. 30, No.2, July, 2016 
111

وحدات المقياس أمكن الحصول على درجة تعبر عن اتجاه الزراع نحســو الإرشــاد الزراعـي.

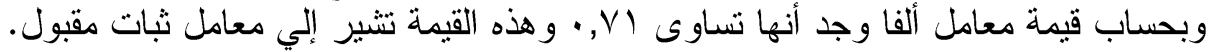

اتجاه زراع الموالح نحو المكافحة الحيوية لحشرة صانعة أنفاق أوراق الموالح.

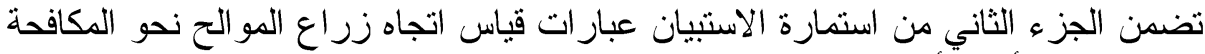

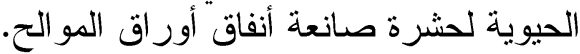

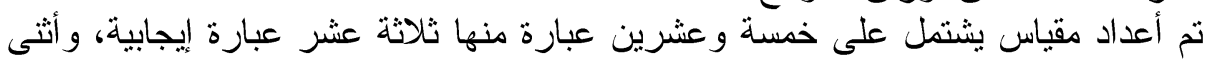

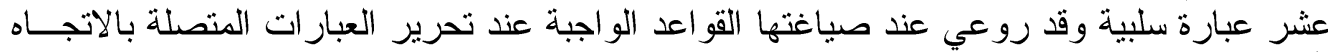

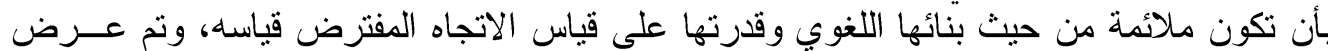

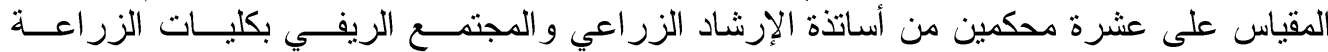

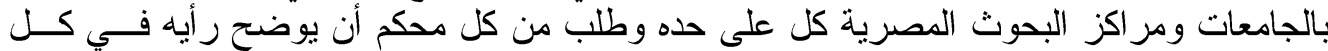

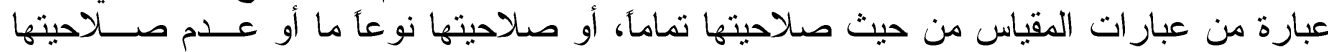

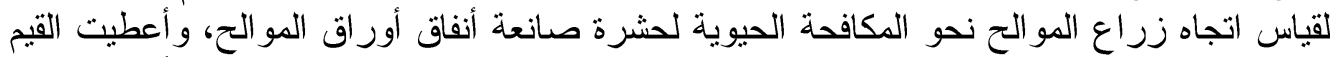

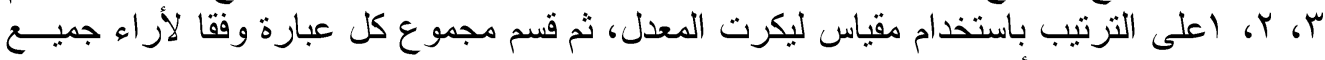

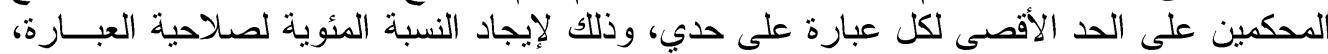

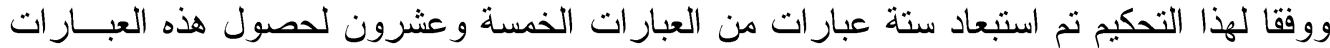

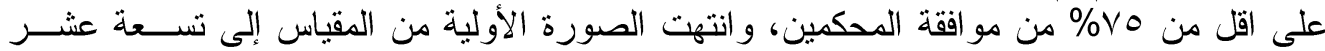

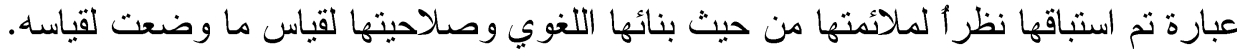

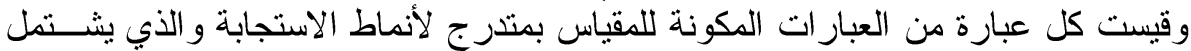

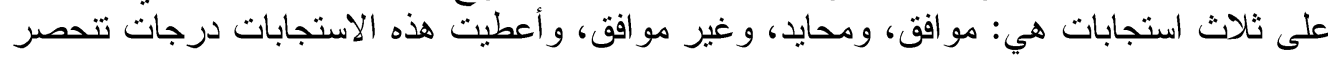

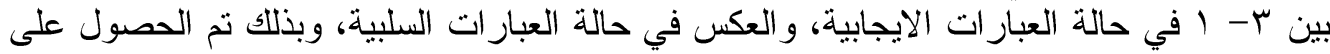

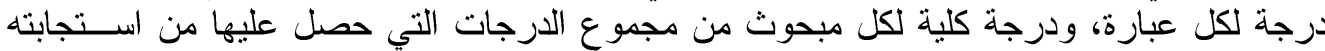

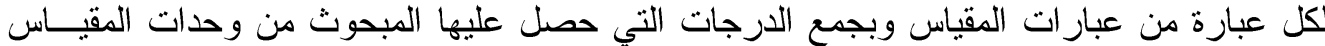

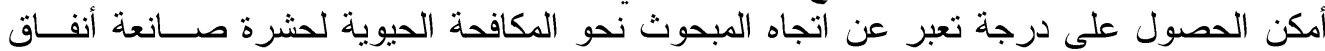

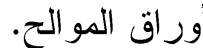

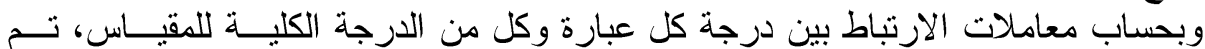

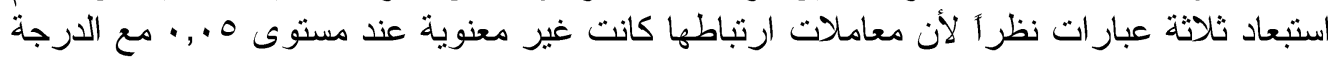

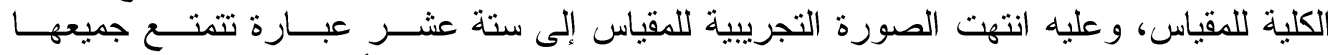

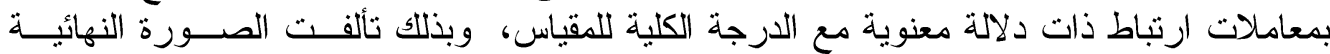
للمقياس من ستة عثر عبارة منها تسعة عبار ات ذات ذات صياغة اليجابية وسبعة عبار ات ذات ذات صــياغة سلبية.

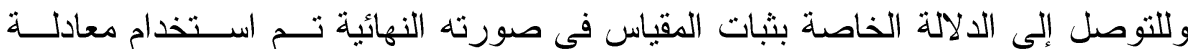

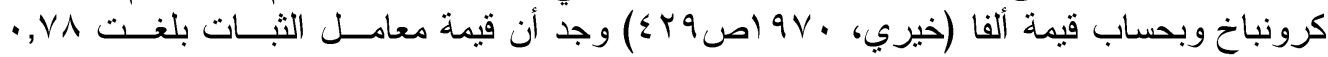

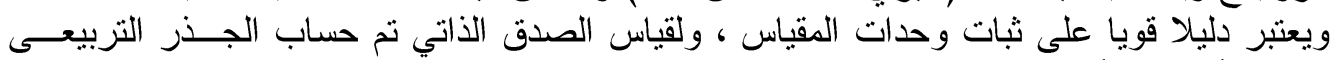

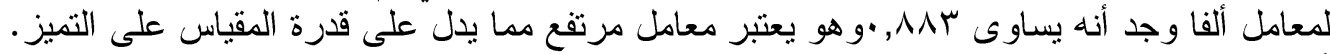

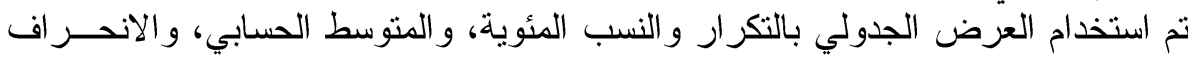

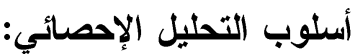

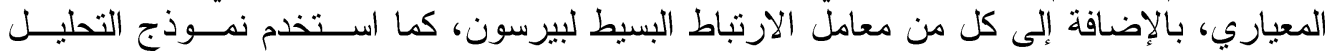

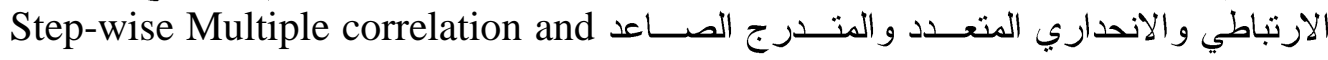
regression

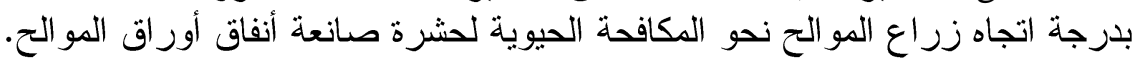

Fayoum J. Agric. Res. \& Dev., Vol. 30, No.2, July, 2016 


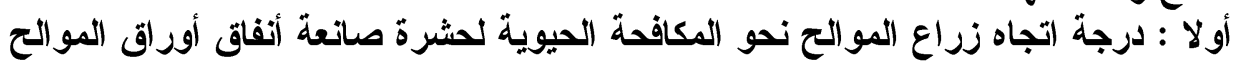

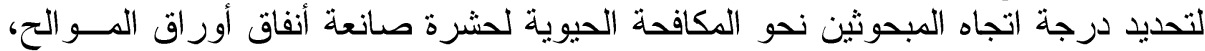

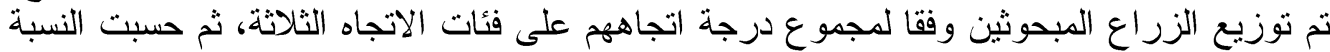

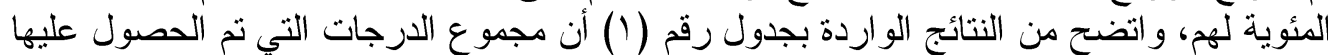

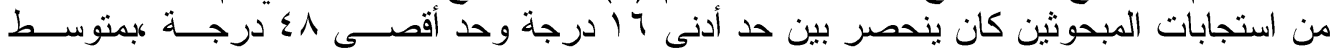

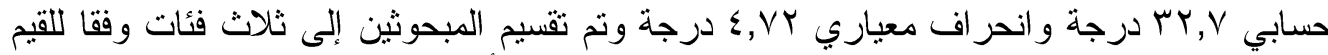

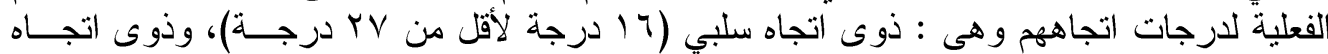

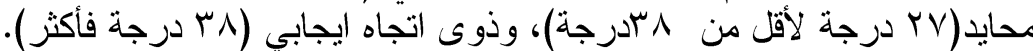

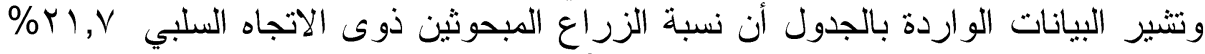

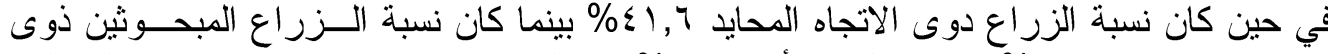

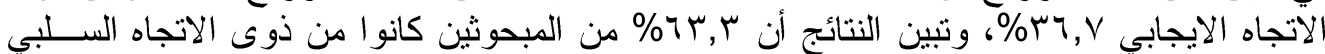

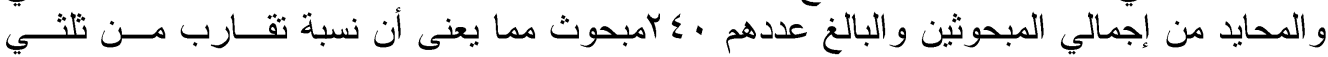
المبحوثين كان اتجاهاتهم سلبية ومحايدة.

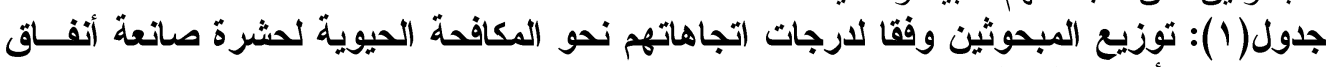
أوراق الموالح

\begin{tabular}{|c|c|c|}
\hline$\%$ & عدد & فئات الاتجاه \\
\hline YI,Y & OY & اتجاه سلبى (T ( 1 - أقل من VY درجة) \\
\hline$\sum 1,4$ & $1 \cdots$ & اتجاه محايد (VY - أقل من ^ץ درجة) \\
\hline$r 7, Y$ & $\wedge \wedge$ & اتجاه ايجابى (^זدرجة فأكثر) \\
\hline $1 \cdots$ & r $\leqslant$. & ل \\
\hline
\end{tabular}

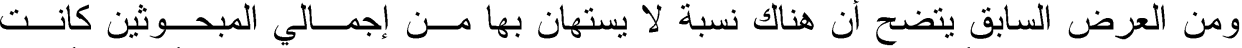

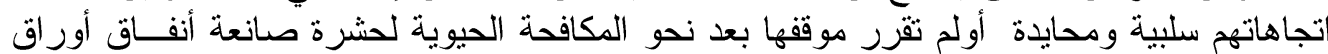

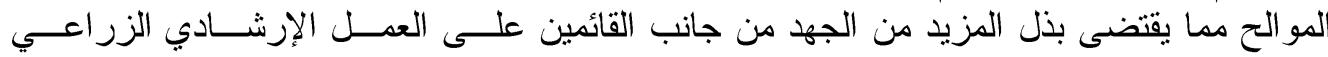

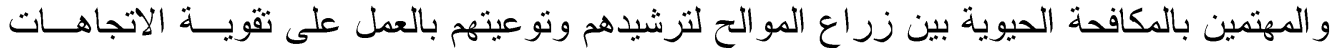

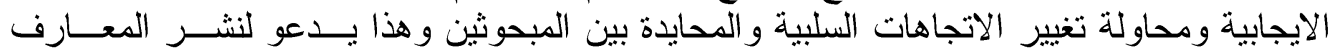

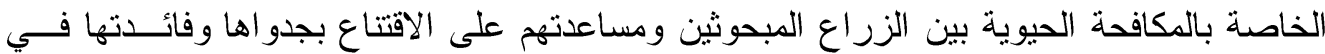

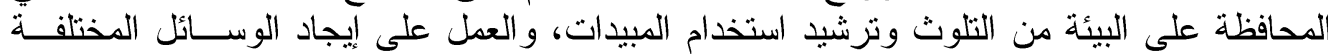

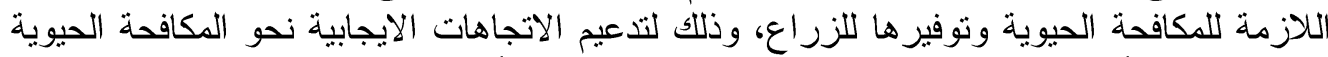

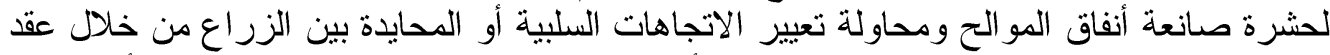

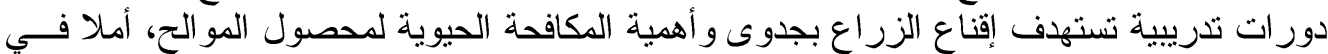

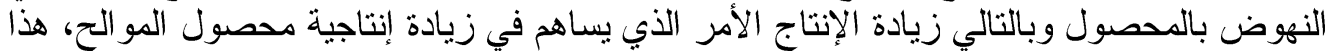

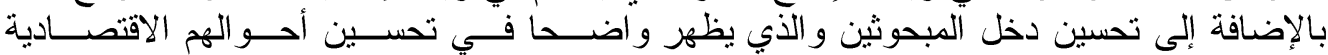

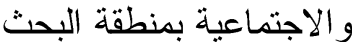
ثانياً: العلاقةة بين المتفيرات المستقلة المدروسة وبين درجة التجاهات زراع الموات الحتح نحو المكافحة

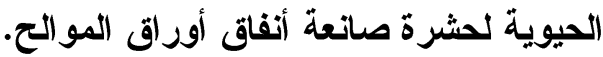

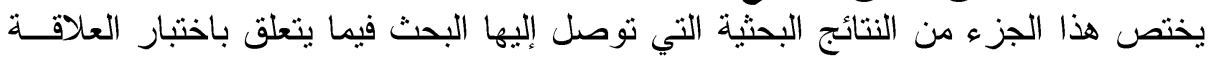

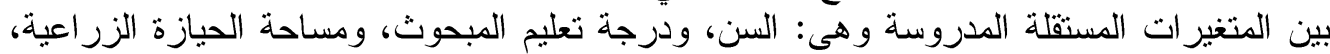

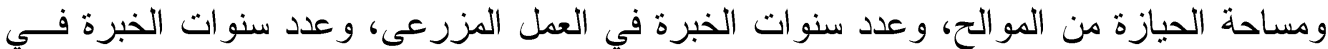
زر اعة المو الح، ودرجة الاتجاه نحو المستحدثات الزرأعية، ودرجة قيادة الر أي، ودرجة الاتجاه نحو الخدي

Fayoum J. Agric. Res. \& Dev., Vol. 30, No.2, July, 2016 
$11 \%$

الإرشاد الزر اعي، وبين درجة اتجاه الزراع نحو المكافحة الحيوية لحثــرة صـــعة أنفــاق أوراق

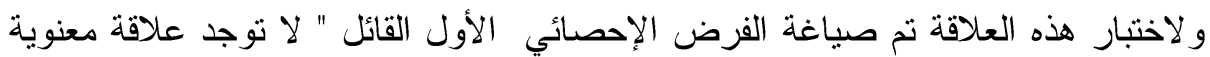

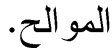

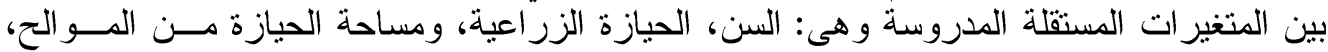

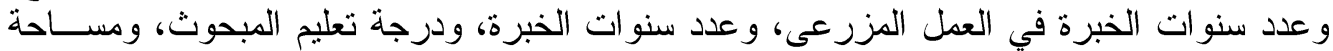

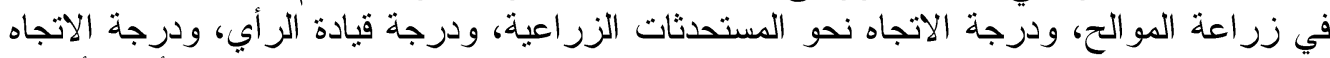

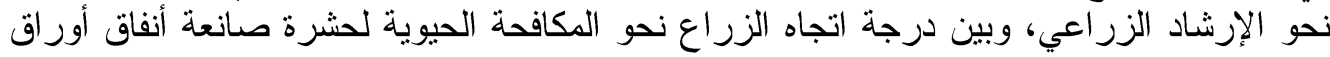

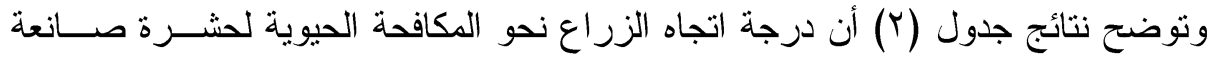
المو الح بمنطقة البحث.

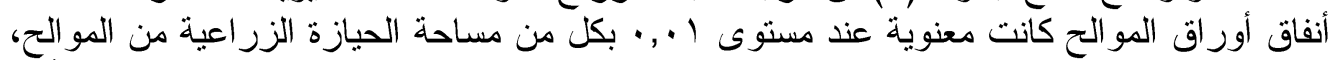

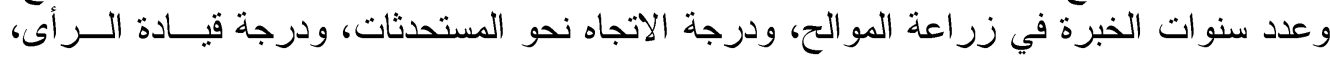

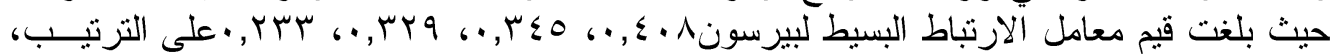

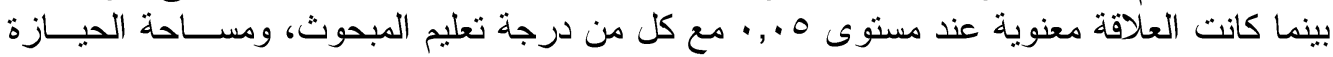

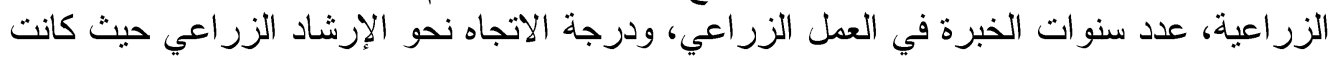

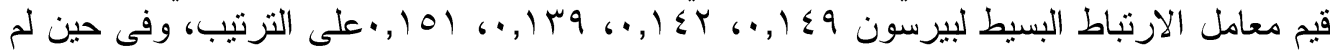
تكن العلاقة معنوية لمتغير السن السن.

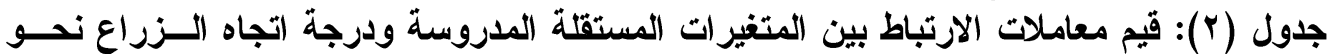

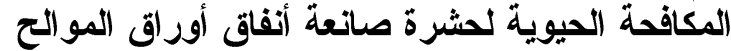

\begin{tabular}{|c|c|c|}
\hline قيم معامل الارتباط & المتفيرات المستقلّة المدروسةّة & م \\
\hline$\cdot, 91$ & السن & 1 \\
\hline$*, 1 \leq 9$ & درجة تعليم المبحوث & $r$ \\
\hline$* \cdot, 1 \leqslant Y$ & مساحة الحيازة الزر اعية & $r$ \\
\hline$* *, \ldots \cdot \wedge$ & مساحة الحيازة من المو الح & $\varepsilon$ \\
\hline$*, 11 r q$ & عدد سنو ات الخبرة في العمل الزر اعي & 0 \\
\hline$* *, r \leqslant 0$ & عدد سنوات الخبرة في زر اعة المو الح & 7 \\
\hline ***, r rq & درجة الاتجاه نحو المستحدثات الزر اعية & V \\
\hline **, & درجة قيادة الر أى & $\wedge$ \\
\hline$* \cdot, 101$ & درجة الاتجاه نحو الإرشاد الزر اعي & 9 \\
\hline
\end{tabular}

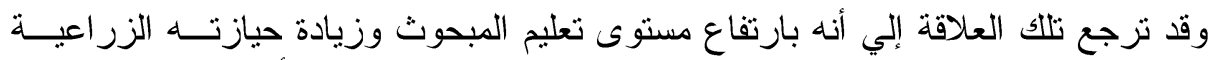

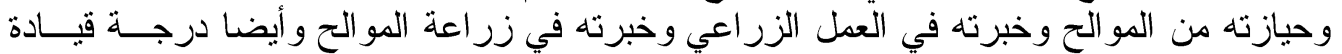

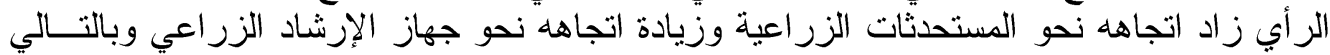

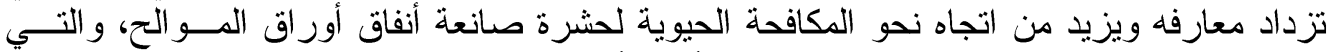

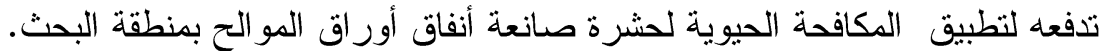

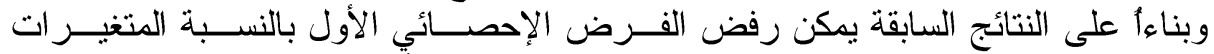

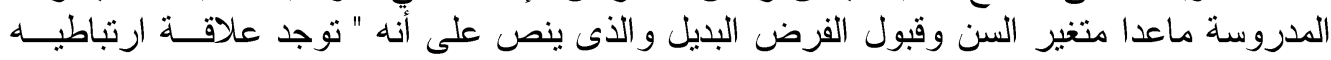

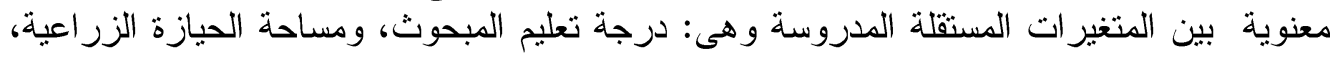

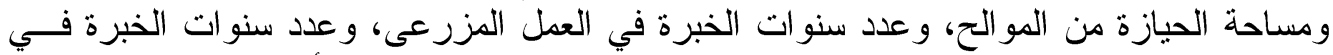

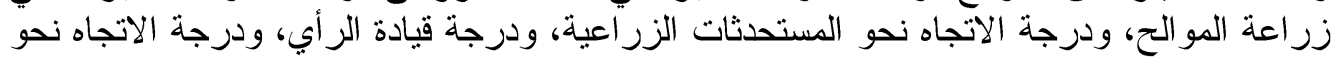

Fayoum J. Agric. Res. \& Dev., Vol. 30, No.2, July, 2016 
$11 \varepsilon$

الإرشاد الزر اعي، وبين درجة اتجاه الزراع نحو المكافحة الحيوية لحشــرة صـــانعة أنفــاق أوراق

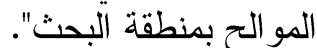

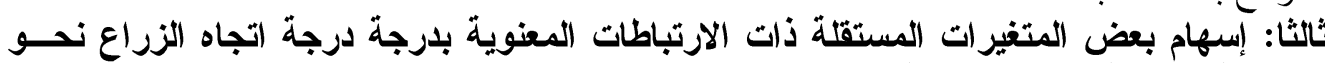

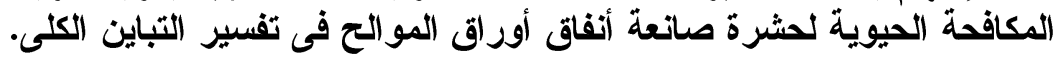

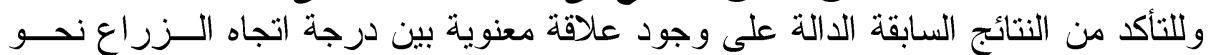

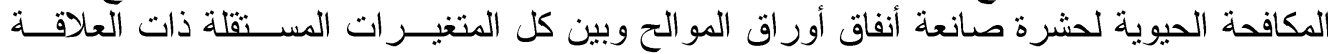

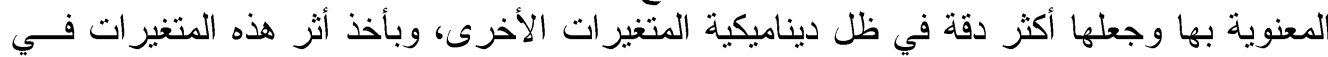

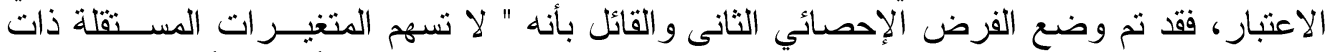

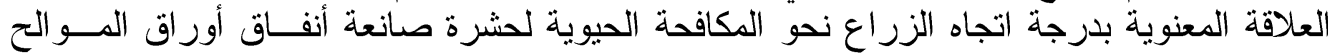

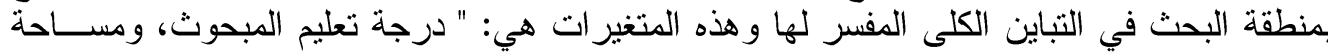

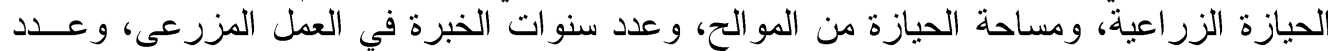

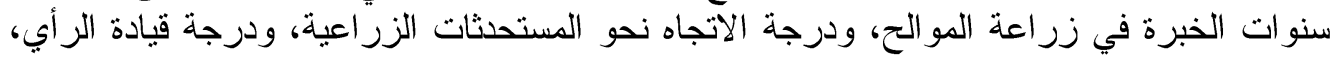
ودرجة الاتجاه نحو الإرشاد في الزراعة الغواعي". و لاختبار صحة هذا الفرض ولإني" لتقدير نسب مساهمة كل من المتغير ات المستقلة ذات العلاقة

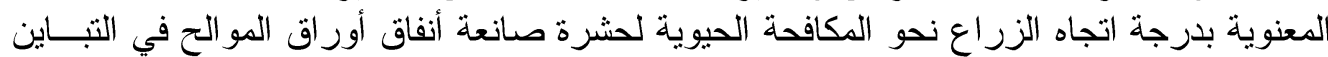

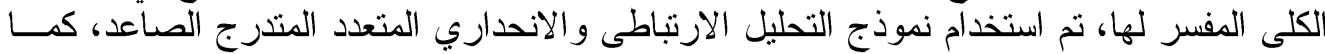
هو موضح بالجدول (T)، ونبين أنه يمكن الإبقاء على أربعة منغير ات تسهم في تفسير التباين الكلى

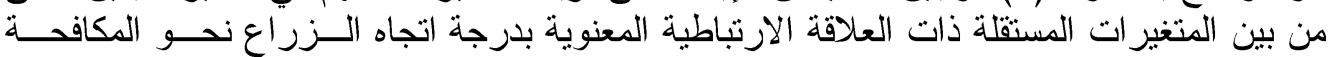

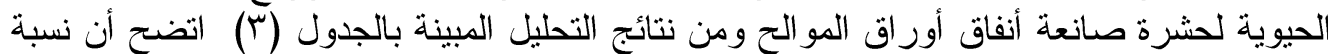

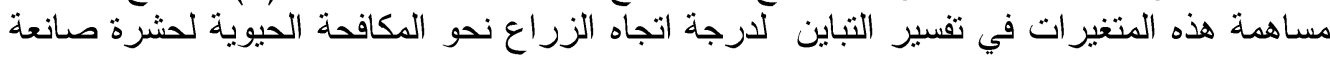

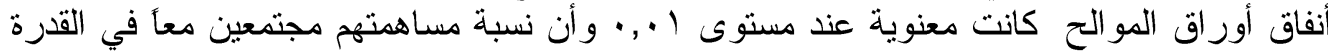

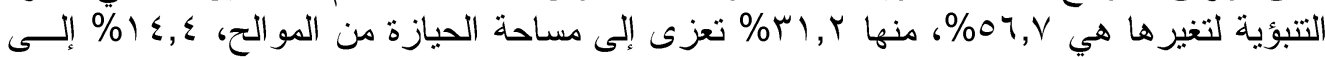

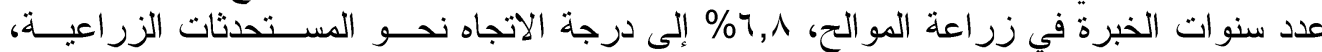
ب, §\% إلى درجة تعليم المبحوث. وطبقاً للنتائج السابقة يمكن رفض الفئ الفرض الإحصائي جزئيًا وقبول الفرض النظري البديل

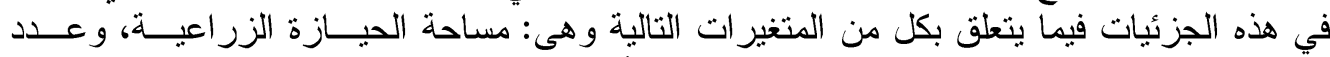

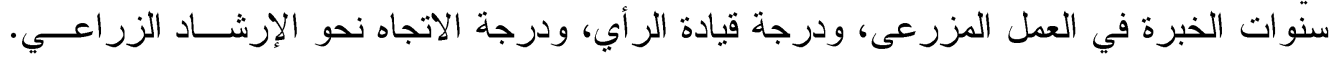

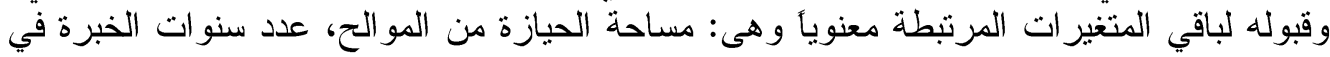

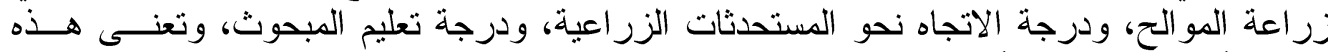

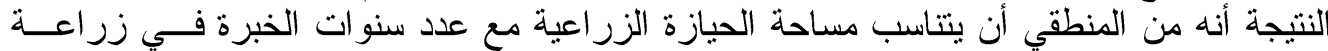

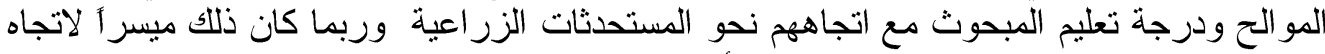

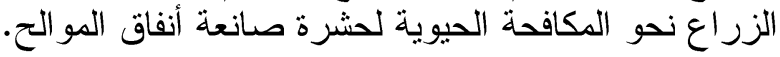

Fayoum J. Agric. Res. \& Dev., Vol. 30, No.2, July, 2016 
110

جدول رقم (ب): التحليل الارتباطي والاتحداري المتعدد المتدرج الصاعد لعلاقة المتغيرات المستقلة

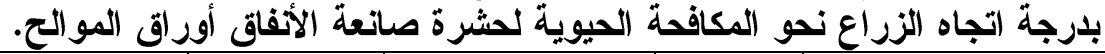

\begin{tabular}{|c|c|c|c|c|c|}
\hline معامل الاتحدار & المفسبة التباين اللمتغير & للتباين المفسر التر للمثية التغير & الارتباط & المتغيرات الاخلية فى التحليل & خطوات التحليل \\
\hline$* * \uparrow 0, V)$. & rI, Y & $r, r$ & $\cdot, 009$ & مساحة الحيازة من المو الح & الخطوة الأولى \\
\hline **YY,VOY & $1 \leqslant, \varepsilon$ & $\{0,1$ & $\cdot, 7 \vee 0$ & زر اعدة المو الح الخبرة فى & الخطوة الثانية \\
\hline **01,Trr & 7,1 & Or,,$\xi$ & $\cdot, V Y \leq$ & المستحدثات الاتجاه نحو الزر اعية & الخطوة الثالثة \\
\hline$* * \leqslant 1,1 \leq \varepsilon$ & $\varepsilon, r$ & $07, \mathrm{~V}$ & $\cdot$, VOT & درجة تعليم المبحوث & الخطة الخعة الخــــة \\
\hline
\end{tabular}

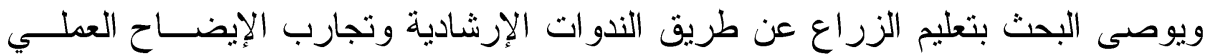

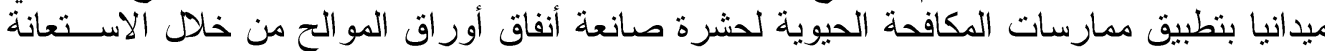

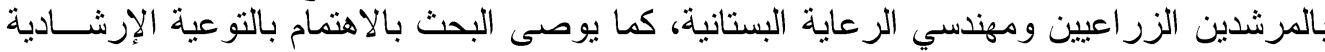

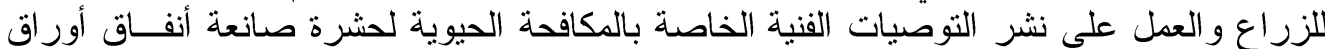
الموالح بين الزراع وإقاعناعهم بتطبيقها في مزارعهم بمنطقة النوبارية.

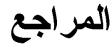
ا- إبر اهيم، عاطف محمد، (دكتور)، الفاكهة المتساقطة الأوراق زر اعتها ورعايتها و إنتاجها، منشــأة

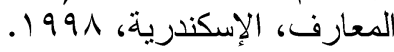

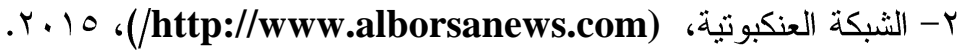

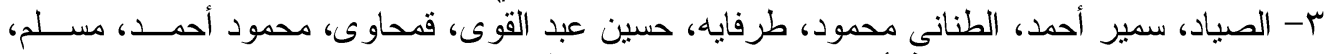

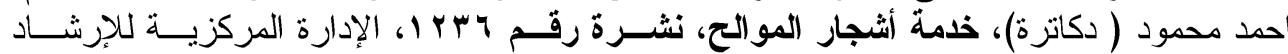

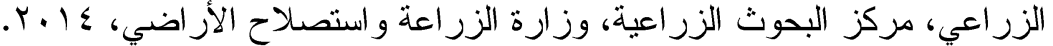

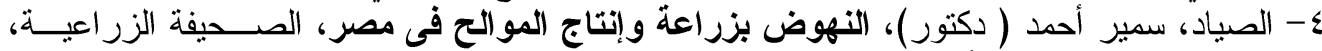

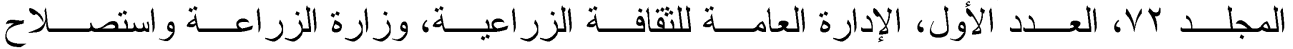

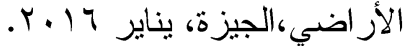

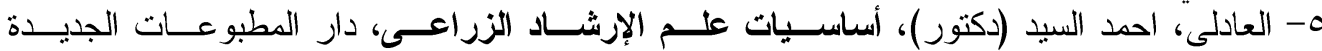

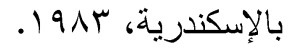
צ- خيرى، السيد محمد (دكتور)، الاحصاء في البحوث النفسية والاجتماعيــة، الطبعــة الر ابعــة، دار

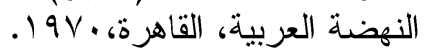

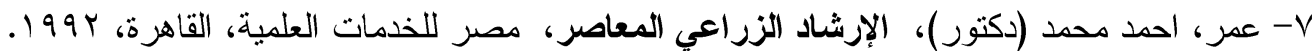

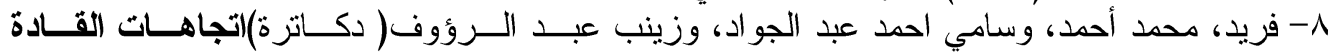
الإرشاديين الزراعيين المحليين نحو الحد من مخاطر تلوث البيئة الريفية بمحافظة القليوبية، مؤتمر

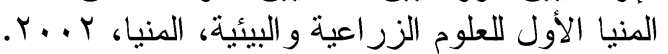

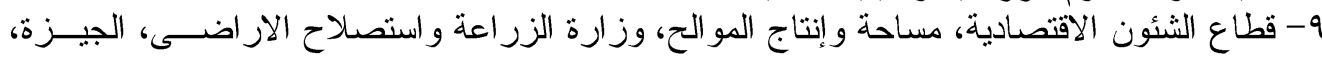
.r. $\{\leqslant$

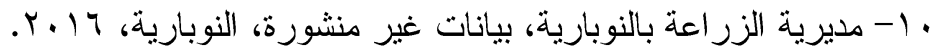

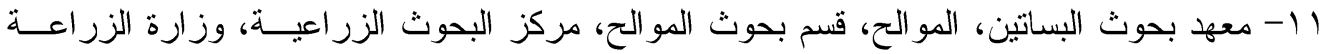

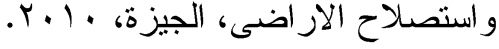

Fayoum J. Agric. Res. \& Dev., Vol. 30, No.2, July, 2016 
119

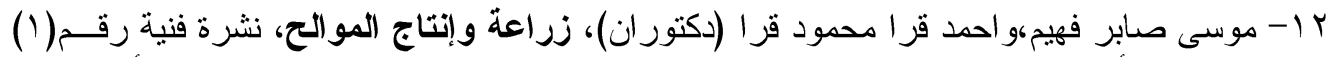

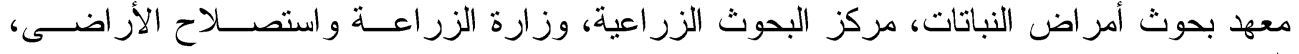

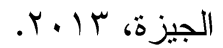

13- Allport.Gordon.Attitude.Begin book.1966.

14- Sumers.Dene(ed) Attitude measurement M c Nelly comp.U.S.A.1970.

15- - Krejcie , R. and E. W. Morgan ' Determining sample size for study

Activities in Educational and psychological measurement, Vol (30), published by college station, Bur ham, north Carolina, USA 1970 .

ملحق (1): وحدات مقياس اتجاه زراع الموالح نحو المكاقحة الحيوية لحشرة صانعة أنقاق أوراق

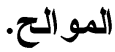

\begin{tabular}{|c|c|c|c|c|}
\hline 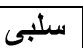 & محايد & | ايجابي & 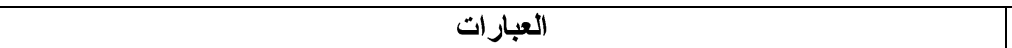 & p \\
\hline$r$ & r & 1 & استخدام المكافحة الحيوية مبيقللث خشرة صانعة انفاق أوراق الموالح & 1 \\
\hline 1 & $r$ & r & استخدام المكافحة الحيوية لحشرة صانعة أنفاق أور اق المو الح بيقلل استخدام المبيدات & r \\
\hline r & $r$ & 1 & |أور اق المو الح ديما مصابة بحشرة صانعة أنفاق أوراق الموالح حتى لو استخدمنا المكافحة & r \\
\hline 1 & r & $r$ & استخدام المكافحة الحيوية بتخلى المز ارع الحقول المصابة بحشرة صانعة انفاق اور اق & $\varepsilon$ \\
\hline 1 & r & r & استخدام المكافحة الحيوية فى مكافحة حشرة صانعة انفاق أور اق المو الح بتقلل من تلوث & 0 \\
\hline r & r & 1 & ما بحبش استخدام المكافحة الحيوية فى مكافحة حشرة صنقيذهانعة أنفاق اور اق المو الح لآنها & 1 \\
\hline 1 & r & $r$ & بيستحسن مكافحة حشرة صانعة انفاق أوراق المو الح حيويا عشن بتجمينا من خطر المبيدات & $\mathrm{V}$ \\
\hline r & r & 1 & |بفضل قوى استخدام المبيدات فى مكافحة حشرة صانعة أنفاق اور اق المو الح عن المكافحة & $\wedge$ \\
\hline 1 & r & r & بفضل أن أهلى يستخدمو المكافحة الحيوية فى مكافحة حشرة صانعة أنفاق اوراق الموالح & 9 \\
\hline 1 & r & r & ياتشعر أن استخدام المكافحة الحيوية في مكافحة حشرة صاعة الموانعة انفاق أوراق الموالح خلت & 1. \\
\hline r & r & 1 & بفضل ديما استخدام المبيدات حشرة صانعة انفاق أوراق المو الح عشان بتوفر المجهود اللى & 11 \\
\hline$r$ & Y & 1 & هانصح جير انى ديما لا يستخدمو ا المكافحة الحيوية عشان ملهاش فايدة & IT \\
\hline r & r & 1 & لهانصح الزر اع يتخلصو ا من مصايد المكافحة الحيوية اللى بيحطو ها بتوع وزارة الزر اعة & 14 \\
\hline 1 & r & $r$ & هانصح زراع المو الح ينفذو المكافحة الحيوية في حقو لهم بنفسهم & $1 \varepsilon$ \\
\hline 1 & r & r & دايما هاقول للزر اع يستخدموا المكافحة الحيوية فى مكافحة حشرة صانعة انفاق اور اق & 10 \\
\hline 1 & r & r & 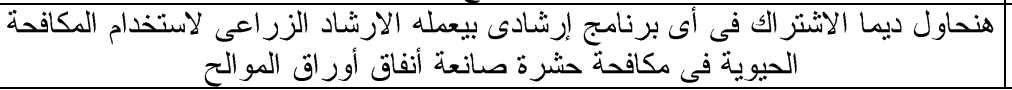 & 17 \\
\hline
\end{tabular}

Fayoum J. Agric. Res. \& Dev., Vol. 30, No.2, July, 2016 
$11 \mathrm{~V}$

\title{
ATTITUDES OF CITRUS GROWERS TOWARD CITRUS LEAF MINER BIOLOGICAL CONTROL AT NUBAREYA
}

\author{
Sayed Abd Elnaby Haikel* Hanan Saad El-Din Hamed* \\ Amera Ahmed Ahmed Eid *
}

Desert Research Center*

\begin{abstract}
Research targeted to identify attitude degree of Citrus leaf miner biological control and determine the relationship between the independent variables studied and degree Attitude of Citrus leaf miner biological control, And determining the contribution of each of the independent variables related to the connectivity in the moral interpretation of kidney contrast to the attitude of citrus growers toward Citrus leaf miner biological control.

The research was conducted in Nubareya, was a systematic random samplewas chosen totaled 240 farmers using equation (Krejcie \& Morgan) $37.5 \%$ of the overall total, Data was collected by a questionnaire by personal. interview, And Percentages, arithmetic mean, standard deviation and coefficient of the simple Pearson correlation, model Correlative analysis and multiple regression and gradual uptrend, were used to analyses Data.

The most important research results are as follows:

- $21.7 \%$ of the respondents had negative attitudes, and $41.6 \%$ had neutral and $36.7 \%$ of them had positive attitude towards the biological control of insect tunnels maker Citrus leaf.

- Attitud degree of citrus growers towards the biological control of insect tunnels maker citrus leaf were significant at the 0.01 level for citrus cultivated area, and number of experience years in the cultivation of Citrus fruits , Attitude toward Agrieytemsion and degree of opinion leadership.

As the value of simple correlation coefficient of Pearson 0.408 , and 0.345 , and 0.329 , and 0.233 , respectively, while the relationship was significant at the 0.05 level with both education degree of size of land holdings , the number of experience years in agricultural work, and the degree of the attitude toward agricultural extension, It ran 0.149 Pearson simple correlation coefficient values, and 0.142 , and $0.139,0.151$, respectively, while the relationship were not significant with age.

- Percentage contribution of these variables in explaining the variance attitudes towards the biological control of insect maker tunnels Citrus leaf were significant at a level of 0.01 and that the contribution ratio gathered together in explane $56.7 \%$ variance of which $31.2 \%$ is attributable to the cultvated of Citrus, $14.4 \%$ to experience years in the cultivation of Citrus fruits, and $6.8 \%$ to attituded toward agricultural innovations, $4.3 \%$ to the degree of the respondent's education.
\end{abstract}

Fayoum J. Agric. Res. \& Dev., Vol. 30, No.2, July, 2016 